\title{
Biosorbent from Biowastes for Heavy Metals Removal from Industrial Effluents
}

\author{
József Paulovics ${ }^{1, *}$, Ljudmilla Bokányi ${ }^{2}$ \\ 1 EMK North Hungarian Environmental Protection Ltd., HU-3792 Sajóbábony, Gyártelep \\ 2 University of Miskolc; HU-3515 Miskolc-Egyetemváros
}

\begin{abstract}
Biosorption has been considered as a potential technology to remove dissolved toxic heavy metals from industrial effluents including machinery manufacturing effluents. The objectives of the present study were to investigate the adsorption behavior of natural and chemically modified sunflower seed hulls (SF) and soybean hulls (SB) for $\mathrm{Pb}^{2+}$ and $\mathrm{Cd}^{2+}$ in mono-cationic systems. Base washing and citric acid (CA) modification were applied to enhance the adsorption capacity of these biowastes. The adsorption ability is sensitive to $\mathrm{pH}$ value in the solution, thus the $\mathrm{pH}$ was adjusted to 5...5.2. SF and SB are promising, inexpensive and effective medium for capturing dissolved $\mathrm{Pb}^{2+}$ and $\mathrm{Cd}^{2+}$ from industrial effluents. Moreover citric acid (CA) modification can increase their adsorption capacity. But this effect cannot be recognized in case of our experiments. The mechanism of biosorption was revealed using FT-IR and zeta-potential measurements.
\end{abstract}

Keywords: Biosorption, heavy metals, sunflower, soybean, lead, cadmium.

\section{Introduction}

Industrial effluents, including machinery manufacturing effluents, can be contaminated with different pollutants, among them heavy metals, as well. Due to stricter regulations on environmental protection there are lower discharge limit values prescribed by responsible regulatory authorities. In case of most industrial activities, the generated wastewater must be treated before being discharged into sewage system or wastewater treatment plant. Mechanical treatment processes (e.g. sedimentation, filtration, phase separation etc.) have an important role during this cleaning process, but in many cases after these treatments dissolved heavy metals remain in low concentration $(<1 \mathrm{mg} / \mathrm{L})$ in the treated wastewater, that is still higher than the prescribed discharge limit values. However, with conventional methods their removal is not economically feasible. Conventional methods (e.g. chemical precipitation, oxidation/reduction, ion-exchange, electrolysis and membrane filtration) have been widely used to remove heavy metals from different kinds of industrial, within it machinery manufacturing effluents, but the phenomenon of biosorption could be an appropriate alternative to these conventional methods in the near future.

Although there are countless research reports on the topic of biosorption process, the majority of them are still at laboratory scale. Nevertheless, finding the appropriate, cheap and effective industrial biosorbents is also an encouraging challenge. Many kinds of biological materials have an affinity for binding inorganic and organic pollutants, so that there is an enormous biosorption potential within the countless types of biomaterials [1; 2]. Different by-products and biowastes 
and their biosorption capacity are also widely investigated, and could be applied in the development of biosorbents.

Our research presented in this article is focusing on two biowastes, i.e. sunflower seed hulls (SF) and soybean hulls (SB), because these materials are the by-products of vegetable oil processing and occur in great abundance in EU and Hungary. The most popular utilization of these materials is energy production (combustion in biomass power plants or production of commercially available briquettes), but new utilisations are possible as potentially value-added products, because they can be converted into effective biosorbents being used in such applications as metal-ion adsorbents for wastewater treatment. It would be important for the creation of the desired circular economy, as well.

Several previously reported studies confirmed that sunflower seed hulls [3; 4] and soybean hulls $[5 ; 6]$ are promising potential biosorbents for different metals, e.g. $\mathrm{Pb}^{2+}, \mathrm{Cd}^{2+}, \mathrm{Zn}^{2+}, \mathrm{Cu}^{2+}$ or $\mathrm{Cr}^{6+}$. The optimal $\mathrm{pH}$ for biosorption in case of both biosorbents is around 5.0, as far as adsorbing capacity is concerned $[3 ; 4 ; 6]$.

According to other studies, sorption capacity of these biosorbents can be increased by chemical modification [7; 8].

\section{Experimental Section}

\subsection{Biosorbents preparation}

Biosorbent materials presented in this paper (i.e. sunflower seed hulls (see Figure 1a.) and soybean hulls) were originated from a vegetable oil production company located in North-Hungary.

\subsubsection{Natural biosorbents}

The sunflower seed hulls and soybean hulls were ground in Retsch SM 2000 cutting mill equipped with a $2 \mathrm{~mm}$ screen and afterwards sieved. The particles with size between 200 and $315 \mu \mathrm{m}$ were stored for further experiments (see Figure $1 \mathrm{~b}$.).

Fractions between 200 and $315 \mu \mathrm{m}$ were repeatedly washed three times in deionized water (50 g of biomass with 3 times $200 \mathrm{~mL}$ of deionized water) in order to remove surface contaminations. The hulls were then dried at $80^{\circ} \mathrm{C}$ for $24 \mathrm{~h}$ and cooled in a desiccator.

\subsubsection{Modified biosorbents}

Adsorption capacity of these biowastes can be enhanced with base washing and citric acid (CA)
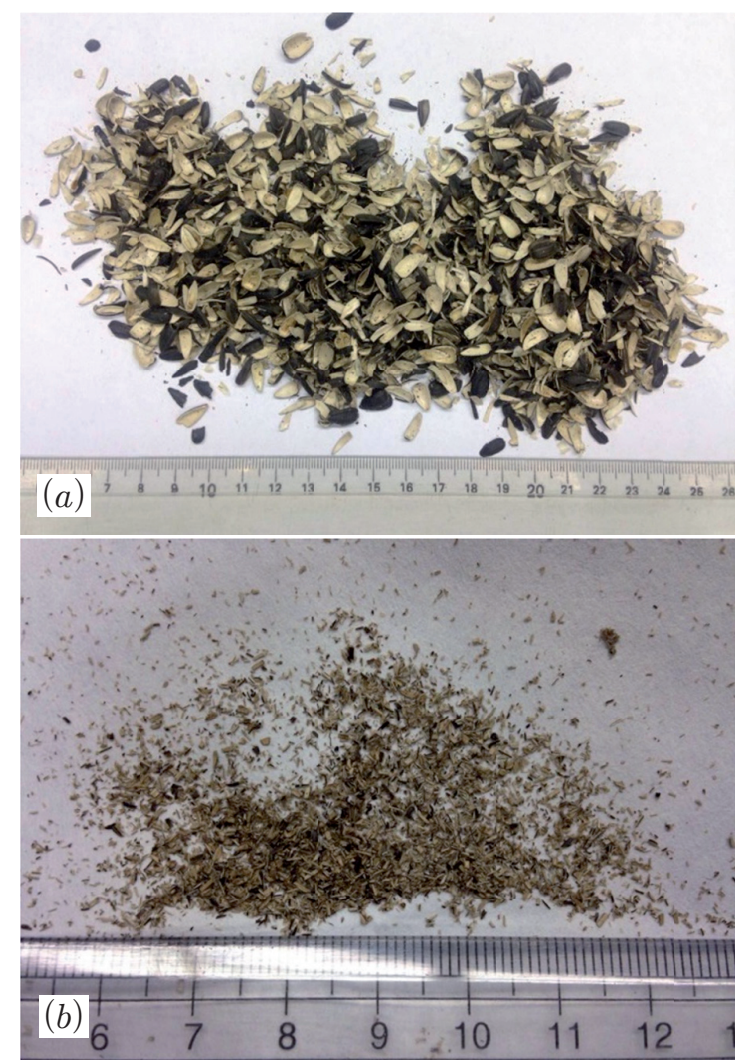

Fig. 1: (a) Natural sunflower seed hulls as biowaste. (b) Ground sunflower seed hulls $(200 \leq x \leq 315 \mu \mathrm{m})$ after drying.

modification according to more authors [7; 8], thus chemical modification of sunflower seed hulls and soybean hulls were carried out according to the similar method previously described by Li et al. [7] (see Figure 2).

$1.0 \mathrm{~g}$ of the sieved hulls was placed into a $250 \mathrm{~mL}$ Erlenmeyer flask containing 0.08 mol/L $\mathrm{NaOH}$ aqueous solution. The mixture was agitated on adjustable incubator shaker (WiseCube WIS-20) at $140 \mathrm{rpm}$ at $25^{\circ} \mathrm{C}$ for 8 hours, and then filtered. Solid phase was washed with deionized water until the $\mathrm{pH}$ of washing water become 5 . After shaking discoloration appeared in the liquid phase. It was most probably caused by the highly soluble organic compounds of the biomass. Filter paper and biosorbents on it were placed into drying oven at $80^{\circ} \mathrm{C}$ for 6 hours. $1.0 \mathrm{~g}$ of base washed and dried biosorbents was added with $150 \mathrm{~mL} 0.6 \mathrm{~mol} / \mathrm{L}$ of citric acid aqueous solution as modified agent, and was heated and maintained at $110^{\circ} \mathrm{C}$ for 1.5 hours in magnetic stirrer. After filtration solid phase was washed with deionized water until the $\mathrm{pH}$ of 
washing water become 5. Finally, the biosorbents were dried at $60^{\circ} \mathrm{C}$ for 24 hours.

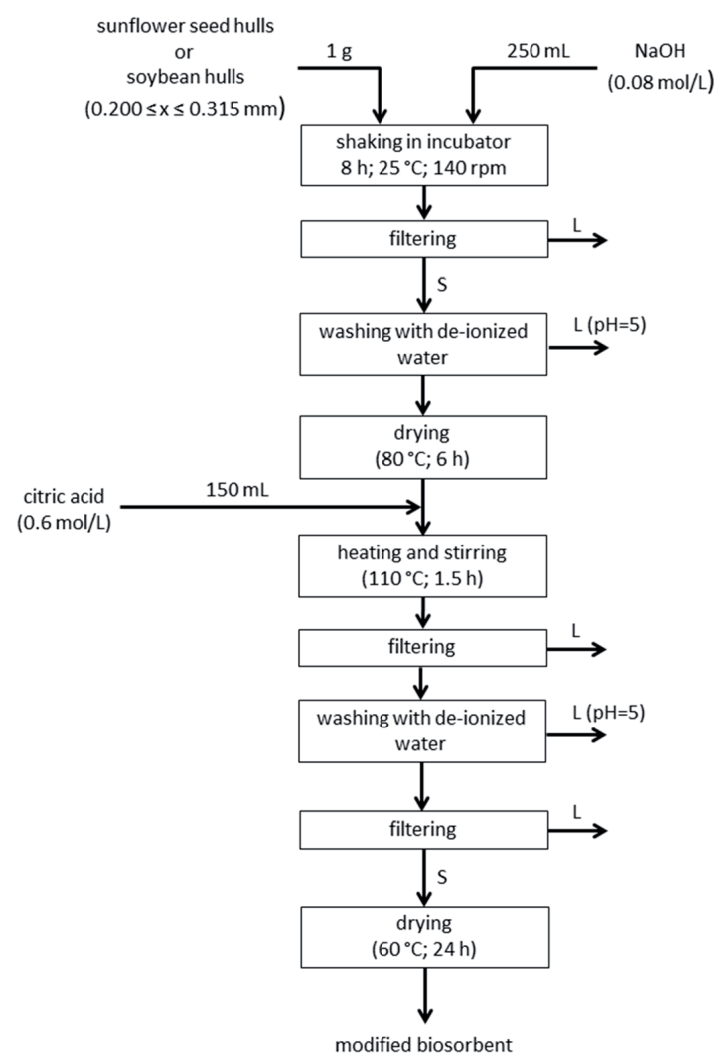

Fig. 2: Base washed and citric acid modification of biosorbents.

\subsection{Solution preparation}

Lead(II) solutions were prepared by dissolving solid lead(II) nitrate powder (VWR Chemicals company) in deionized water.

Cadmium(II) solutions were prepared by dissolving solid cadmium nitrate tetrahydrate powder (SIGMA-ALDRICH) in deionized water. The initial $\mathrm{pH}$ values of the working solutions (before the biosorption) were adjusted between 5.0 and 5.2. Diluted $0.1 \mathrm{M} \mathrm{NaOH}$ and $0.1 \mathrm{M} \mathrm{HCl}$ were used for $\mathrm{pH}$ adjustment.

\subsection{Biosorption experiments}

Biosorption of cadmium and lead on the surface of SF, SB, modified SF (M-SF) and modified SB (M-SB) were investigated in mono-cationic systems. Batch equilibrium sorption experiments were performed in $250 \mathrm{~mL}$ Erlenmeyer flasks. The initial $\mathrm{Pb}^{2+}$ or $\mathrm{Cd}^{2+}$ concentration were $20 ; 50 ; 80 ; 100 ; 200 ; 300$; 400; 600; 800 and $1000 \mathrm{mg} / \mathrm{L}$. The concentration of biomass was $1 \mathrm{~g} / \mathrm{L}(100 \mathrm{mg}$ biomass in $100 \mathrm{~mL}$ solution). The suspension was shaken at $150 \mathrm{rpm}$ for $18 \mathrm{~h}$ at the temperature of $25^{\circ} \mathrm{C}$ by using adjustable incubator shaker WiseCube WIS20.

\subsection{Determination of sorption isotherm}

Suspended solid particles were removed after the biosorption experiments by using filter paper (grade: 1,289; diameter: $150 \mathrm{~mm} ; 84 \mathrm{~g} / \mathrm{m}^{2}$ ). After the filtration some drops of $\mathrm{HNO}_{3}$ were added to the separated liquid samples. Prior to the testing in ICP-OES or AAS, all the samples were refrigerated at approximately $4^{\circ} \mathrm{C}$.

The concentrations of the metals in liquid phase were subsequently determined by using inductively coupled plasma optical emission spectrometer (ICP-OES), type: SPECTRO CIROS VISION at KISANALITIKA Laboratory Services Ltd. in case of biosorption on natural biomass, and by using atomic absorption spectrometer (AAS) at Institute of Chemistry, University of Miskolc in case of the modified biomass.

The measured metal concentrations were used to calculate the adsorption capacity (qea $\left[\mathrm{mmol} \mathrm{g}^{-1}\right]$ ) of the biosorbent applying the following mass balance equation:

$q_{e q}=\left(c_{0}-c_{e q}\right) \cdot \frac{V}{m}$

where: $c_{0}, c_{e q}, V$ and $m$ are initial metal concentration ( $\left.\mathrm{mmol} \mathrm{L} \mathrm{L}^{-1}\right)$, metal concentration at equilibrium (mmol $\left.\mathrm{L}^{-1}\right)$, the volume $(\mathrm{L})$ of the solution and weight (g) of adsorbent, respectively.

\subsection{Other measurements on the biosorbents}

Zeta-potential of SF and SB were measured before and after conditioning with magnetic stirrer for 10 minutes by Zeta Potential Analyzer (Brookhaven Instruments Corporation ZetalPALS, purchased by GVOP-3.2.1-2004-04-0219/3.0. Project; Project Leader: Dr. Ljudmilla Bokányi) in deionized water and in mono-cationic model solutions ( $\mathrm{C}_{0}$, pb or $\mathrm{C}_{0}$, cd was $800 \mathrm{mg} / \mathrm{L}$ ) at the Department of Bioprocessing and Reaction Techniques, Institute of Raw Material Preparation and Environmental Processing, University of Miskolc.

Fourier transforms infrared (FT-IR) spectra were used to identify functional groups on the surface of tested biowastes. FTIR analysis was performed by JASCO FT/IR-4200 Spectrometer before and after biosorption experiments with $\mathrm{C}_{0}, \mathrm{pb}=1000 \mathrm{mg} / \mathrm{L}$ or 
$\mathrm{C}_{0, \mathrm{Cd}}=1000 \mathrm{mg} / \mathrm{L}$ at our Institute.

\section{Results and Discussion}

\subsection{Sorption isotherm measured points}

It can be seen from Figure 3 a.) and b.) that the natural SF and SB do have sorption ability towards dissolved cadmium and lead-ions, but there is no evidence where they reach their maximum capacity. The sorption capacity of the natural biomasses at equilibrium can reach $0.30 . .0 .45$ $\mathrm{mmol} / \mathrm{g}$ in case of $\mathrm{Pb}^{2+}$ and $\mathrm{Cd}^{2+}$ in mono-cationic systems, if the maximum $\mathrm{C}_{\text {eq }}$ is not higher than $3 \mathrm{mmol} / \mathrm{L}$. It can be stated that there are no significant differences between the sorption ability of SF and SB. Remarking that these qea values cannot be considered as maximum uptake values $\left(q_{\max }\right)$, further examinations are required at higher $\mathrm{C}_{\mathrm{eq}}$ values to determinate $\mathrm{q}_{\text {max. }}$

No enhanced sorption ability can be recognized in case of the applied chemical treatment of biosorbents, with the exception of $\mathrm{Cd}^{2+}$ sorption on SF (see Figure 3 c.) and d.)). These results contradict with the data from literature. However, its reason has not been clarified yet, it needs further investigation. One of the possible explanations can be the significant decrease of $\mathrm{pH}$ value after the biosorption, since the initial $\mathrm{pH}$ decreased from 5 to about 3. The adsorption ability is highly sensitive to $\mathrm{pH}$ value in the solution, thus repeating the chemical treatment is recommended with $\mathrm{pH}$ buffering.

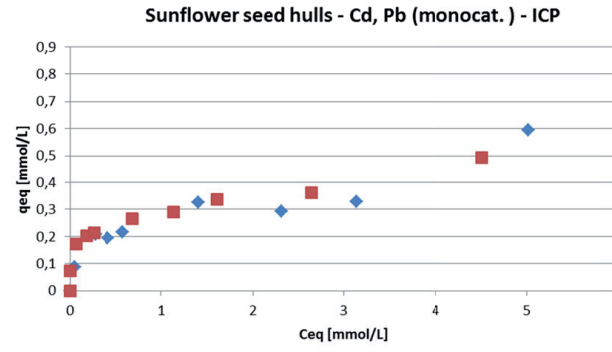

Soybean hulls - Cd, Pb (monocat.) - ICP

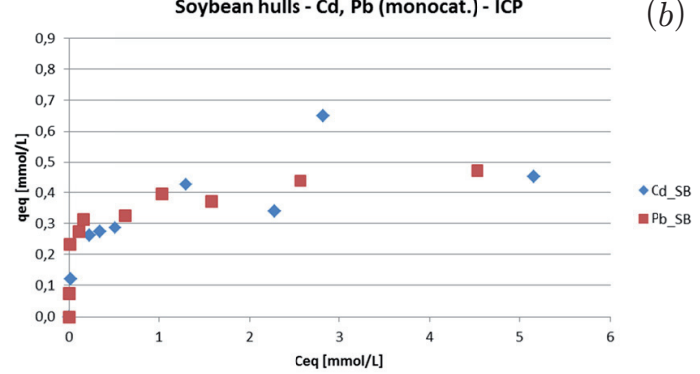

$\bullet$ Cd_SF
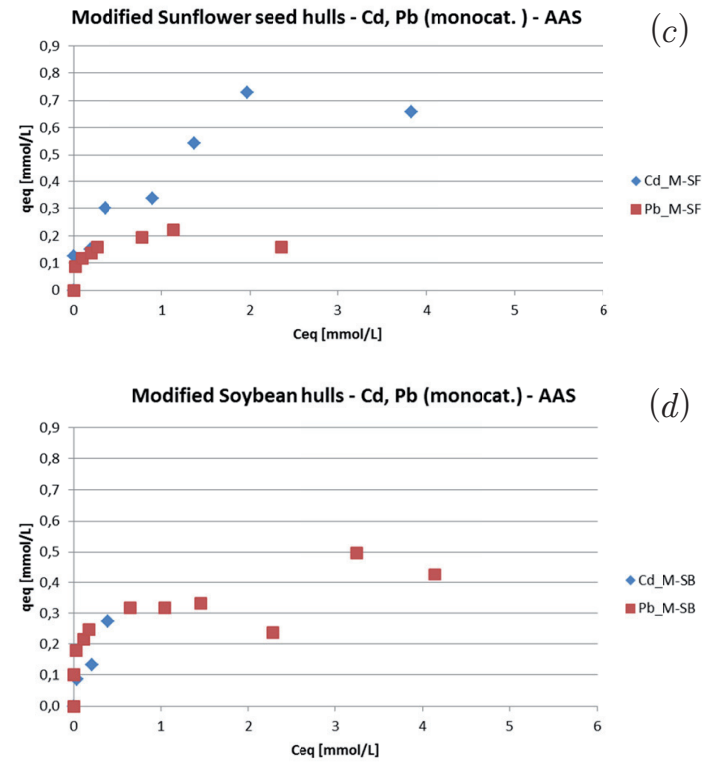

Fig. 3: (a) Sorption capacity of SF. (b) Sorption capacity of SB. (c) Sorption capacity of M-SF. (d) Sorption capacity of M-SB.

\subsection{Mechanism of biosorption}

FT-IR helps to identify functional groups in the tested materials. The FTIR spectra of modified biosorbents can be seen in Figure 4 before and after biosorption in case of both metals.
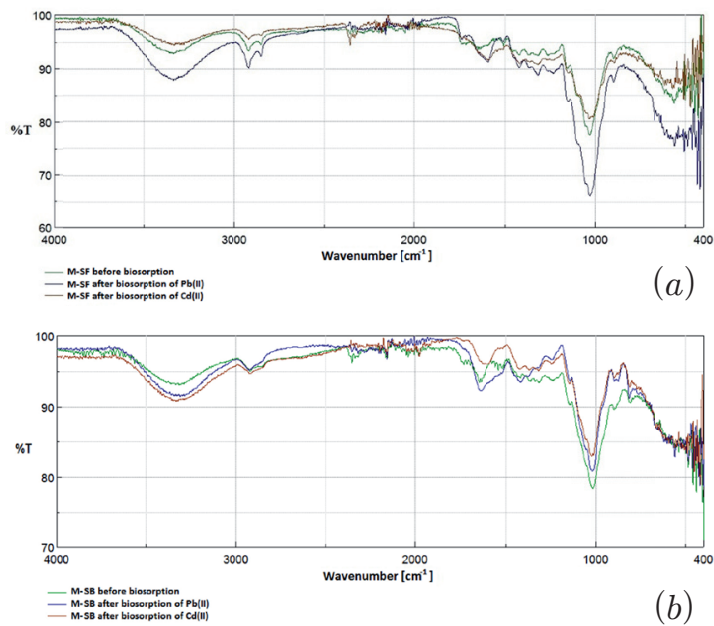

Fig. 4: (a) FTIR spectra of modified SF. (b) FTIR spectra of modified $S B$.

Both modified SF and modified SB have peaks at similar wavenumbers and when the biomasses were loaded with $\mathrm{Pb}^{2+}$ and $\mathrm{Cd}^{2+}$, the FT-IR spectrum showed some changes. The highest deviation 
from the unloaded biomasses curve appears at around $1030 \mathrm{~cm}^{-1}$, which corresponds to $-\mathrm{C}-\mathrm{O}$ alcohols and carboxylic acids [3]. The broad peak observed at $3444 \mathrm{~cm}^{-1}$ corresponds to the $\mathrm{O}-\mathrm{H}$ stretching vibrations of cellulose, pectin, absorbed water, hemicellulose and lignin [5]. These infrared measurements also revealed the presence of such functional groups as amide groups $\left(1651 \mathrm{~cm}^{-1}\right)$, $-C=O$ from carboxyl or ester groups $\left(1739 \mathrm{~cm}^{-1}\right)$ [3]. Peaks appeared at similar wavenumbers in case of natural SF and SB [9], thus the applied modification did not considerably influence the appearance of newer functional groups responsible for binding.

\subsection{Zeta-potential measurements}

$800 \mathrm{mg} / \mathrm{L}$ initial concentration was chosen for the measurement of zeta-potential before and after biosorption [10; 11]. Zeta-potential of SF showed the highest increase after biosorption in case of both metals, thus we can draw the conclusion that the adsorption mechanism of $\mathrm{Pb}^{2+}$ and $\mathrm{Cd}^{2+}$ on SF has an electrostatic character. This phenomenon remains after the modification, as well. According to our measurements SB and modified SB uptake these metals with a specific sorption (see Tab. 1). Negative surface charge before biosorption of SB and SF increased in absolute value after the chemical treatment indicating the appearance of newer negative charges.

Tab. 1: Zeta-potential measurements before and after biosorption.

\begin{tabular}{|l|l|l|l|l|}
\hline & SB & Modified SB & SF & Modified SF \\
\hline Before biosorption & -4.72 & -5.62 & -13.29 & -16.72 \\
\hline $\begin{array}{l}\text { After biosorption of } \\
\text { Pb(II) }\left(C_{0}=800 \mathrm{mg} / \mathrm{L}\right)\end{array}$ & -2.42 & -1.96 & -1.97 & -2.03 \\
\hline $\begin{array}{l}\text { After biosorption of } \\
\text { Cd(II) }\left(C_{0}=800 \mathrm{mg} / \mathrm{L}\right)\end{array}$ & -4.60 & -3.44 & -4.84 & -3.60 \\
\hline
\end{tabular}

\section{Conclusions}

It was proved that the applied biosorbents (sunflower seed hulls and soybean hulls) are able to reduce the $\mathrm{Pb}^{2+}$ and $\mathrm{Cd}^{2+}$ concentrations in model solutions. They can reach a theoretical maximum uptake of $0.35 \ldots . .0 .50 \mathrm{mmol} / \mathrm{g}$. These uptake capacities are not outstanding among other biosorbents, but these ones have several advantages (e.g. inexpensive, great abundance, macroscopic, etc.), thus their further investigations are extremely justified. Their application as effective biosorbents can be possible in case of industrial effluents, though more experiments are needed in laboratory and semi-industrial scale prior to the industrial application.

According to more sources, chemical modification of these biosorbents can cause increases in the sorption ability, but with the applied chemical modification we were not able to manage to enhance it. On the contrary, we recognized it rather decreasing. One of the possible explanations for this phenomenon can be the significant decrease of $\mathrm{pH}$ value after biosorption, since the initial $\mathrm{pH}$ decreased from 5 to about 3. The adsorption ability is sensitive to $\mathrm{pH}$ value in the solution, thus we are planning to repeat our experiments applying $\mathrm{pH}$ buffering.

The main adsorption mechanism of $\mathrm{Pb}^{+2}$ and $\mathrm{Cd}^{2+}$ on sunflower seed hulls has electrostatic character, while the biosorption on soybean hulls took place with a specific sorption according to our zeta-potential measurements. These phenomena did not change after the chemical modification of biosorbents.

FT-IR spectra showed that SF, SB, modified SF and modified SB have similar functional groups on their surface, for example $-\mathrm{C}-\mathrm{O}$ alcohols and carboxylic acids, $\mathrm{O}-\mathrm{H}$ groups, amide groups and $-\mathrm{C}=\mathrm{O}$ from carboxyl or ester groups.

\section{Acknowledgments}

This research was supported by the cooperation between the Institute of Raw Material Preparation and Environmental Processing, University of Miskolc and the EMK North Hungarian Environmental Protection Ltd., Hungary. The described work/ article was carried out as part of the "Sustainable Raw Material Management Thematic Network - RING 2017", EFOP-3.6.2-162017-00010 project in the framework of the Széchenyi2020 Program. The realization of this project is supported by the European Union, co-financed by the European Social Fund.

\section{References and Notes}

[1] Dhankhar, R., Hooda, A. (2011). Fungal biosorption - an alternative to meet the challenges of heavy metal pollution in aqueous solutions, Environ. Technol., 32, 467-491.

[2] Gadd, G.M. (2009). Biosorption: critical review of scientific rationale, environmental importance and significance for pollution treatment. J. Chem. Technol. Biotechnol., 84, 1328.

[3] Witek-Krowiak, A. (2012). Analysis of temperature-dependent biosorption of Cu2+ ions on sunflower hulls: Kinetics, equilibrium and mechanism of the process. Chemical Engi- 
neering Journal 192, p. 13-20.

[4] Mohammed, A. A. (2015). Biosorption of Lead, Cadmium, and Zinc onto Sunflower Shell: Equilibrium, Kinetic, and Thermodynamic Studies, Iraqi Journal of Chemical and Petroleum Engineering Vol.16 No.1, 91- 105. ISSN: 1997-4884

[5] Blanes, P., Bordoni, E., González, J., García, S., Atria, A., Sala, L., Bellú, S. (2016). Application of soy hull biomass in removal of $\mathrm{Cr}(\mathrm{VI})$ from contaminated waters. Kinetic, thermodynamic and continuous sorption studies, Journal of Environmental Chemical Engineering 4, 516-526.

[6] Kishor, P., Vilas, P., Patil, N., Vijay, M. (2012). Adsorption of Copper (Cu2+) \& Zinc (Zn2+) Metal lon from Waste Water by Using Soybean Hulls and Sugarcane Bagasse as Adsorbent. International Journal of Scientific Research and Reviews, 1(2), 13-23. ISSN: 2279-0543

[7] Li, J., Chen, E., Su H., Tan T. (2011). Biosorption of Pb2+ with Modified Soybean Hulls as Absorbent. Chinese Journal of Chemical Engineering, 19(2) 334-339

[8] Zhu B., Fan, T., Zhang, D. (2007). Adsorption of copper ions from aqueous solution by citric acid modified soybean straw. Journal of Hazardous Materials 153 (2008) 300-308

[9] Paulovics, J., Sebe, E., Siska, O., Bokányi, L. (2016). Comparison of biosorption of lead and cadmium on sunflower seed hulls, soybean hulls by-products and algae. Biotechnology \& Metals: 4th International Scientific Conference (e-Proceedings), 70-77, ISBN: 978-80-89883-01-1.

[10] Siska, O. (2017) BSc thesis (Supervisors: Dr. L. Bokányi and J. Paulovics. University of Miskolc.

[11] Sebe, E. (2017) BSc thesis (Supervisors: Dr. L. Bokányi and J. Paulovics). University of Miskolc.

\section{Biographical notes}

József Paulovics was born in 1983. He graduated from University of Miskolc, Hungary as environmental engineer in 2007 and process engineer in 2008. He started his PhD studies at University of Miskolc, Hungary in 2008 and finished the training period in 2012. Since 2012 he has been working as an R\&D engineer for the EMK North Hungarian Environmental Protection Ltd., Hungary. He is dealing with environmental processes, process engineering, biosorption, wastewater treatment, waste incineration. Author of more than 10 papers.

Dr. Ljudmilla Bokányi graduated as mineral processing engineer from Moscow Metallurgical University in 1979. Since then she has been working for the Department of Process Engineering of University of Miskolc, Hungary. Her PhD was devoted to coal flotation modelling. She is dealing with environmental processes, bioprocesses, flotation, water treatment and plasma gasification as well. She spent her post-doc period in 1993 at University of Leeds, Great-Britain. Guest researcher in NIRE, Tsukuba, Japan and TU Berlin. Associate Professor, she established Department of Bioprocessing and Reaction Techniques within the Institute of Raw Materials Preparation and Environmental Processing, and has been leading it. Head of Doctoral Sub-programme "Environmental Processing" she is invited professor in many European universities, as well as coordinator of many national and international research projects. Corresponding member of the International Organising Committee of International Coal Preparation Congress since 2001, editor-in-chief and member of many scientific and professional bodies and committees. Author of more than 130 papers. 